\title{
Integrating Product-Safety Curriculum to Enhance Design and Reinforce Engineering Ethics
}

\section{Prof. Kenneth L. d'Entremont, University of Utah, Department of Mechanical Engineering, Ergonomics and Safety Program}

Dr. d'Entremont has worked in industry for over twenty-five years. During this period, he investigated mishaps and conducted vehicle handling and crash testing. For over ten years, he was Corporate Product Safety Manager for a large designer, manufacturer, and international distributor of powersports vehicles and products. He was responsible for both active tasks (such as design reviews, product specifications, sign-offs, and standards development) and reactive tasks (such as product investigations, safety recalls, and regulatory affairs) for all of their products worldwide.

\section{Dr. Andrew S Merryweather, University of Utah}

Andrew S. Merryweather is director of the Ergonomics and Safety Program at the University of Utah and Assistant Professor in the department of Mechanical Engineering where he teaches and directs research in the areas of biomechanics, human factors, musculoskeletal injury prevention and human modeling. Dr. Merryweather obtained his Ph.D. degree in Mechanical Engineering at the University of Utah in 2008 as a NIOSH Trainee in Occupational Injury Prevention. Over the past 12 years Dr. Merryweather has managed significant research projects investigating musculoskeletal injuries in the workplace, assistive technologies for persons with disabilities, adaptive technology development, robotics and human-system interactions 


\title{
Integrating Product-Safety Curriculum to Enhance Design and Reinforce Engineering Ethics
}

\begin{abstract}
The National Society of Professional Engineers' (NSPE) Code of Ethics for Engineers has, as its first Fundamental Canon, the admonition: Hold paramount the safety, health, and welfare of the public. Despite recognizing and accepting this, the majority of today's engineering students are given little guidance on safety. Product-safety engineering is more than compliance, legality, reliability, expense, quality, or simply increasing design margins of safety.
\end{abstract}

To address this gap, a course was developed to raise awareness and provide engineering students with concepts and tools useful to product-safety engineering. This course is structured to help students make sound and rational decisions affecting the safety of product users by applying safety concepts and industrial experience.

Unlike well-established, core engineering classes, product-safety engineering is not determined by objective scientific criteria. Rather, it is ultimately decided by value systems which vary regionally, temporally, and from person-to-person. This requires students to think clearly and express effectively their rationale and decisions to others.

Students are presented with historic product-safety issues, engineering ethics, changing world demographics, intended use, classification of safeguards, safety hierarchies, post-sale responsibilities, Haddon matrices, risk management and analysis, and industry standards. A comprehensive approach to product safety is emphasized through student group projects evaluating the safety of a product of their selection using tools learned in the course. Qualified guest speakers introduce or reinforce course topics.

Course examples are used to show that conditions leading to product-safety issues rarely arise from advanced technologies alone, but instead from failures to properly follow engineering basics such as fastener design, testing programs, development processes, misunderstanding product use, and ignoring failure modes.

This course is taught from the perspective of a fast-paced, innovative design and manufacturing corporation with worldwide distribution. Effective points of influence for product-safety evaluations within the Engineering Design, Development, and Testing Process (EDDTP) are described.

Students learn to think critically and to study beyond today's necessarily restrictive technical curricula so that they are prepared to take responsible positions in modern corporations and benefit the public. Students are encouraged to innovate when addressing product-safety concerns - a skill that will be necessary to responsibly address the new and unique productsafety challenges of our ever-changing, complex world. 
Introduction

The National Society of Professional Engineers (NSPE) has in its Code of Ethics, as its first Fundamental Canon, the admonition: Hold paramount the safety, health, and welfare of the public [1]. This ideal is widely regarded as being the ethical, moral, or simply the right thing to do. It resonates with most members of society including practicing and soon-to-be-practicing engineers of all disciplines.

Although the above is recognized and accepted, today's engineering students are given little instruction and guidance in their formal engineering educations about designing and manufacturing safe products or about practicing engineering ethically. Most engineering students are told to make safe and non-defective products without being taught how to do so. Product-safety engineering is not necessarily compliance, legality, reliability, expense, quality, or simply increasing margins of safety. It is more than this and should be integrated into the engineering-design process. This paper describes a product-safety engineering course, with engineering ethics, developed to raise awareness of and to equip engineering students with tools specific to engineering safe products and designing with public wellbeing at the core.

Introduction to Product-Safety Engineering and Engineering Ethics was created to address this gap in engineering education. Much of this course's curriculum evolved from industrial experience at a fast-paced, international designer, manufacturer, and distributor of durable consumer/hard goods. The products were innovative - frequently industry leading - and were produced with a focus on product-safety function integrated into the engineering-design process. Consequently, the curriculum for the new course is targeted to this type of engineering environment.

This product-safety engineering course benefits by being within an engineering department offering courses in ergonomics, human-factors, system safety, and industrial safety. Therefore, some material also important to product-safety engineering is covered in other courses.

Engineering challenges during product design, development, and testing — as well as ethical dilemmas regarding product safety that may confront a practicing engineer - are addressed both by the professor and by specialized guest speakers.

\section{Product Safety}

The NSPE clearly states the professional obligations that an engineer has to society. Both experienced and entry-level engineers should have no problem with accepting these as being noble and correct. However, for focusing on the safety of the public, the young engineer or engineering student is given no guidance on what safety truly is.

For the engineer, it is helpful to identify what product safety is not. For example, product safety is not necessarily quality, reliability, compliance, or even legality. Nor is product safety simply increasing a margin of safety. Each of these can be a characteristic completely apart from safety. Low-quality and low-cost products can be completely safe. Completely reliable systems may be unsafe. Compliance criteria contained in regulations and standards may be completely arbitrary 
or of unknown origin. Many laws are nonsensical or completely without rational basis. Many products have failed in failure modes never anticipated by the design team.

Some examples of each of these are discussed in the course. However, a quick example of the inability to rely upon standards is provided here. A company with truly innovative products may well find itself designing products for which no standards exist. In this case, it is obvious that standards compliance cannot guide product-safety concerns directly. That company may, perhaps, seek indirect guidance from portions of standards for similar products and, thereby, piece together some design and performance criteria for their new product. Consequently, the resulting assemblage of criteria will be endorsed by no standards-development organization. This is uncharted standards-compliance territory and may cause some risk-averse companies to balk at introducing such an innovative product.

The Product-Safety Engineering Course and Approach

This course has been offered for three years ${ }^{1}$ in the University of Utah's Department of Mechanical Engineering. This course is a technical elective for upper-division students and graduate students within the Department, and has been taken by students in other engineering disciplines and combined-degree programs.

The approach taken in teaching product-safety engineering is comprehensive in nature and takes into account the safety system consisting of the numerous opportunities and elements that can positively affect - either alone or in combination - the safety of a product.

The course's description is below:

This course provides an introduction to elements of product-safety engineering and management within a fast-paced and innovative international design, manufacturing, and distribution company subject to significant regulatory and public scrutiny. The product being engineered is a durable consumer good. Topics covered include concepts regarding product safety and the role of the product-safety professional in the design, development, testing, manufacturing, and post-manufacturing stages of a product. The importance of engineering ethics to a practicing engineer are discussed. A comprehensive approach to product safety is taught including the influences of designers, manufacturers, sales and marketing personnel, executives, regulators, consumers, and the use environment. The need for effective and consistent information, instructions, and marketing messaging for a product is stressed. Students will study the role of compliance with standards and regulations as well as the failure of standards developers to keep standards current.

\footnotetext{
${ }^{1}$ For its first offering, the course, ME EN 5960/6960 "Special Topics," was offered as a joint product safety and industrial safety course. It has since been taught twice as a product safety-only course.
} 
Corporate teams (engineering design/development, manufacturing, testing, purchasing, logistics, sales, marketing, accessories, etc.) are able to design and construct an entire system of components for the consumer to understand, operate, buy, maintain, transport, and use the product. For this reason, it is strongly advised that the function of product-safety engineering be thoroughly integrated into the Engineering Design, Development, and Testing Process (EDDTP) — and beyond when needed. Therefore, product safety analyses and reviews must be performed during the engineering design, development, and testing of products rather than just at the end of the processes. In this way, a product's final design and its associated safety characteristics may be guided to a desired end point, rather than simply reviewed once time runs out.

In traditional engineering-design textbooks, the attribute of safety is rightfully recognized as a necessary characteristic of any product or system. However, authors generally say little more than what amounts to "make safe products" or "be careful not to make defective products." The authors do not wish to reference a few specific instances of engineering-design textbooks doing this since doing so may make the arbitrarily selected authors appear culpable for a much-larger problem in engineering-education literature. This problem is the dearth of knowledge of and understanding of product-safety engineering.

Without being told how to design safe products, engineers are simply left to their own devices. It is reasonable to say that virtually all engineers - both practicing and soon-to-be practicingare ethical people who truly want to make safe products. Therefore, the goal of the course is to simply provide engineering students with the tools they need to implement the decisions they want to make in the first place.

The authors are unaware of similar product-safety engineering courses despite searching for such. Thus, this course appears to be unique. The course can be divided into two complementary portions. The first portion of the course discusses product-safety concepts or theory. The second portion of the class addresses the application of material learned in the first portion.

\section{Portion I. Concepts}

\section{A. Product Safety and Engineering Ethics}

The teaching of ethics is difficult to undertake without encroaching on indoctrination, morality, and metaphysics. Typical areas of ethics studies are personal, business, medical, scientific, and legal. Engineering ethics does not receive the same amount of attention as do these areas. In fact, ABET [2] only requires, for engineering-program certification in 2018-2019, the teaching of "professional ethics" for civil-engineering programs and "legal, regulatory, privacy, ethics, and human behavior" for cyber-engineering programs. The curricula of other engineering disciplines have no such requirement. 
The ultimate question engineers must ask themselves is: "To whom is allegiance owed?" Most engineers are unprepared to reason through the following: Engineers are paid by their organizations for their professional services, but engineers are also members of a greater society and have obligations to fellow citizens.

Engineering students are also confronted with the possibility, however improbable, that whistleblowing may be the only ethical choice out of a future professional situation. Years ago, the need for an engineer to "blow the whistle" on an employer had an infinitesimal probability. Today, however, the need for whistleblowing has become a less-remote - even imaginable [3] response to protect oneself. For instance, there are presently two employees of a large automobile manufacturer serving prison time and owing large fines for various charges stemming from an emissions-cheating scandal [4], [5]. Actions do have consequences. It is better to learn this axiom early, rather than late, in an engineering career. Engineering students are reminded of this throughout the course.

The engineering-ethics guidance provided to students in the course may be summarized in the four practical points below.

1. Work hard and do a good job

2. Do the right thing

a. Be able to sleep at night

b. Be able to look yourself in the mirror

3. Make executives earn their salaries

4. Do NOT go to jail!

The first point is fairly self-explanatory and covers the engineer's obligations to the employer. The second point covers obligations to the engineer her/himself as a person and to society. The third point involves the employer's obligation to the engineer to participate in decision making at critical moments. The final point reiterates engineers' responsibilities to themselves.

Regarding point two, the engineer may find it useful to ask: Would I want my loved ones using this product? Both the answer itself and the amount of time needed to answer the question are telling. The third point, making executives earn their salaries by bringing important matters to their attention — even if they do not wish to be involved it them - is an important role played by engineering staff since improper decisions can be so damaging to an organization. Remember that bad choices can easily cost organizations hundreds of millions of dollars - billions of dollars in the case of the emissions scandal [6]. Unless an engineer is explicitly authorized to make such decisions, $\mathrm{s} /$ he must demand that executives step up. About the final point, although students laugh when it is delivered with some tongue-in-cheek intent, events adduced above clearly demonstrate that the incarceration of engineers can happen. 


\section{B. What is Product-Safety Engineering?}

Product-safety engineering is a relatively unique engineering discipline because safety depends upon subjective criteria. It is a "soft" engineering branch unlike "hard" branches such as thermodynamics, fluid mechanics, and dynamics.

Unfortunately, the study and application of product-safety engineering is not subject to hard-andfast physical laws. In fact, rather than being based on objective truth, many safety criteria are, at best, developed through consensus. At worst, safety criteria are subjective whims.

\section{Value Systems and Product-Safety Criteria}

Engineers are routinely faced with meeting multiple objectives during the EDDTP; however, product safety is unlike many other objectives. For example, if consumers want a product to be both light in weight and red in color, but Engineering only produces a product that is light and blue, the consumer is not completely satisfied. The consumer is happy that the product is lightweight, but is unhappy that the product is not red. The consumer is, however, unharmed by the product's color despite not being happy about it.

Value systems are influenced by many factors, including upbringing, geographic location, historic time, life experiences, reflective thought, education, knowledge, and even prejudices. What might have been considered safe in the 1950s is not considered safe today and what is now considered safe may not be regarded as safe in the 2030s. To drive this point home, the course includes a historic review of various changes in the safety of food [7], consumer products [8], and automobiles [9].

\section{Product-Safety Concepts}

When either establishing or assessing the safety of a product, the engineer must know what the product is intended to do. Strangely enough, this is not always done. For some products in the United States, it is not necessary to explicitly state the purpose of a product - even when the product is regulated. There are notable exceptions, for example, the U.S. Food and Drug Administration [10]. Such intended-use statements are also needed to $c \epsilon$ mark [11] a product for import into or sale in Europe. Regardless of the explicit need to state intended use, it is a good engineering practice to determine it before the EDDTP. Without knowing what the product is to do, engineers cannot design the most appropriate level of safety into the product.

The first two product-safety engineering methods taught to the class involve the classification of safeguard devices as written by Barnett and Barroso [12], [13]. These are quantitative methods used to categorize safeguard devices by characteristics. The first analysis method [12] is a simple, yet powerful, means for assessing individual safety devices, or for comparing a set of possible safety devices, based upon their intrinsic natures. Each safety device is evaluated regarding whether that device increases safety, leaves safety unaffected, and/or decreases safety. 
A single device may exhibit one, two, or all three of these characteristics. From this evaluation, the appropriate type of safeguard device may be determined and incorporated into the design.

The above method only applies to individual safety devices. It does not apply to systems of safety devices. For such systems, it is necessary to look at the functional hierarchy [13] of safeguarding systems. When multiple safety devices are integrated into a system, then the system level can be determined. System levels include zero-order, first-order, ..., to $\mathrm{n}^{\text {th }}$-order. Each higher-order system enhances the efficacy of its immediate lower-order system.

Another aspect of product-safety engineering taught is the use of the safety hierarchy as a design tool. The safety hierarchy is as close to being objective "safety science" as any method. It is well known to practicing engineers. However, Barnett and Brickman [14] identified 39 distinct "safety hierarchies" in 1985. These safety hierarchies differ in the number of steps as well as their priorities. Therefore, it is necessary to identify which safety hierarchy is being discussed when using that term. Those authors produce a consensus safety hierarchy which is the version unwittingly recited by many engineers.

Although the safety hierarchy can provide useful guidance at an elementary level, its utility is truly limited. The safety hierarchy does not indicate when an on-product warning sign, for example, is sufficient to not use a barrier guard to safeguard a saw blade. Most engineers would agree that eliminating a hazard may be the best safety option, but eliminating hazards may also result in eliminating desirable features. Therefore, a safety hierarchy sometimes provides useful guidance about abstract design issues, but rarely proves useful for making practical engineeringdesign decisions.

One product-safety concept taught in the course is the potential for product users to become dependent upon a safeguard device, to potentially misuse it in different ways [15], and perhaps increase risk. Other considerations for the design engineer include safeguard selection, human motivation, and standardization [16]-[21].

A final conceptual tool taught to students is the Haddon Matrix [22]. This tool is excellent for doing a "gap" analysis. The matrix studies three phases of an accident: Pre-Event, Event, and Post-Event. For each accident phase, the potential accident-mitigation factors are listed for each of four factors: Human, Product, Physical Environment, and Socio-Economic Environment. For example, if the event is a motor-vehicle accident, then during the Event phase of the accident, the factor of Product can mitigate injury to the human by providing seat belts and air bags. Working through the complete matrix illustrates gaps in the overall system where greater safety could perhaps be provided by designers, users, policy makers, and society itself. 


\section{Portion II. Application}

\section{E. Integrated Product Safety}

Once the conceptual aspects of product-safety engineering have been covered, the class is prepared to look at the application of those methods within an engineering-design process. The process used in this course is shown as Phase 3 in Figure 1 as the Engineering Design, Development \& Testing Process (EDDTP).

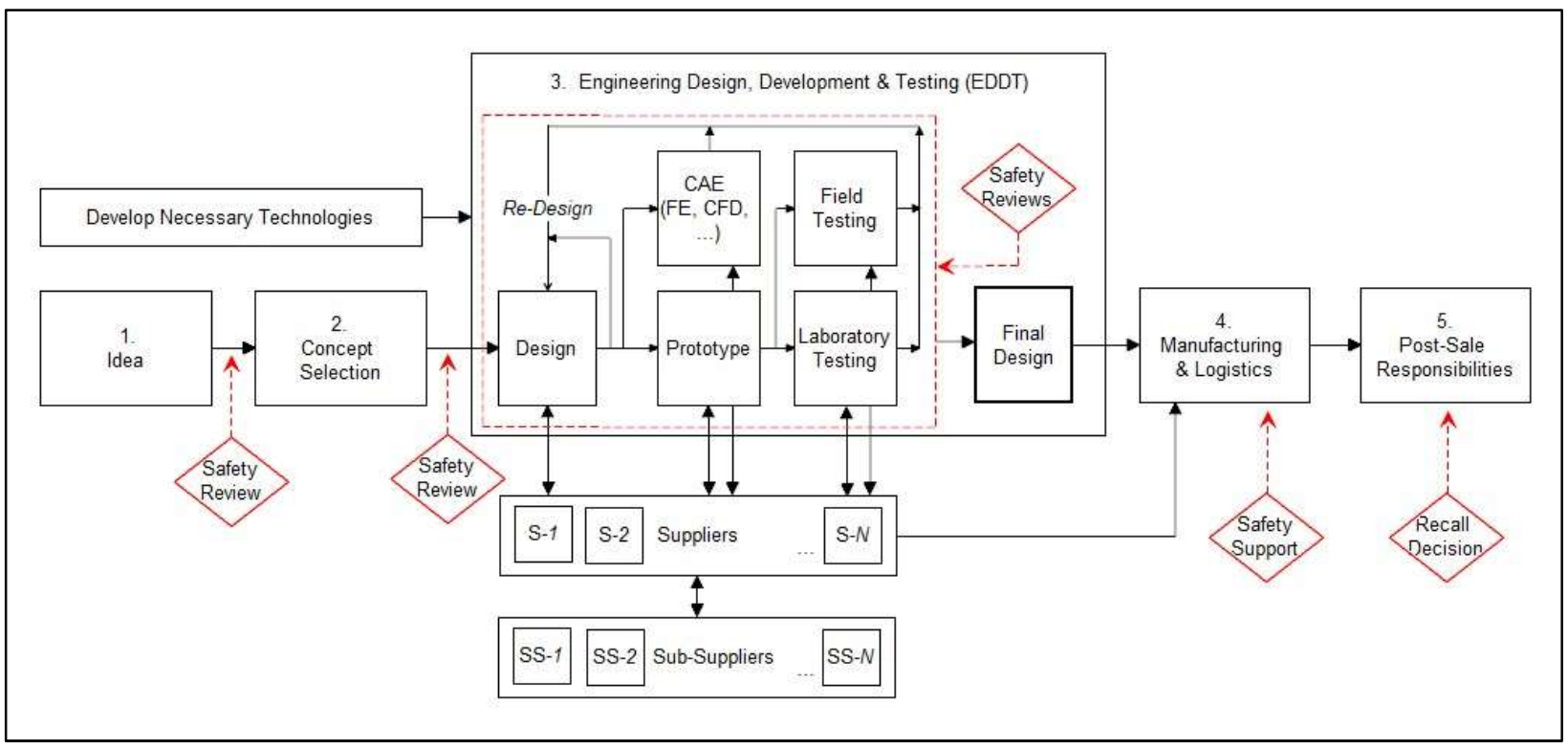

Figure 1. Typical Product-Development Phases where Safety is Embedded in the Process

The figure shows the interrelations between the phases and components used in successful product development. Fundamentally, it is not significantly different from general engineeringdesign processes in literature, e.g., [23], [24], [25]. Phases 1 and 2 are typical to engineering processes in that a product is envisioned and then a rough form of that product is chosen for design and development, respectively. Running in parallel with Phases 1 and 2 is the potential need to develop a technology for use in the particular product. If an immature technology is inserted into the product-development process, which is on a strict schedule, then product safety may be only one of many product characteristics to be compromised. The product safety is reviewed at the end of each phase before going onto the next. At these early phases, it may be sufficient for the engineers and other project staff to simply acknowledge the product-safety issues that will be faced by the project. Although solutions will be needed before final-design release, a detailed plan of action may not be required yet.

Phase 3 is the stage of most concern to the design-engineering team. It is here that the product is designed, re-designed, prototyped, analyzed, tested, and finally released to Manufacturing. This block shows interactions with suppliers and the suppliers' interactions with sub-suppliers. The 
figure shows the explicit need for testing in the field and in the laboratory. There are numerous incremental reviews of product safety during Phase 3. During these incremental reviews, those working on product safety must study the present design iteration for known issues, likely upcoming issues, and potential issues using knowledge and experience. Such a knowledge base may come from those with experiences at other companies, in other industries, and from different projects within the same organization. Field and laboratory test reports must be studied unless test engineers are able to candidly brief product-safety engineers on issues experienced or reported with prototype product. When the product design is complete, one final product-safety review is conducted to assess the final design before proceeding to Phase 4. Prior to leaving Phase 3, it is essential that no unresolved product-safety issues remain.

Phase 4 is the manufacturing of the product and, while design and safety engineering may think that their work is concluded, numerous manufacturing issues may arise from unfinished design details requiring support from the product-safety engineer.

Phase 5, for product-safety personnel, is the stage where a released product's performance in the hands of consumers must be monitored. Reports of failures, incidents, and injury are collected and analyzed. This is a vital aspect of product-safety engineering. It is essential that a company know how a product is performing in the field with real users. This post-sale monitoring and remediation effort is discussed later. Information collected during this phase will also be useful to designers of future products.

For some products, the product-safety engineer may be brought into the design project starting at Phase 3. This is especially true if the new product is based on an existing product and only minor changes are expected to the product, such as with model-year changes. However, if the product is completely new to the company or if the product is without an established category in the marketplace, then the product-safety engineer must become involved earlier than Phase 3. Perhaps involvement should begin in Phase 2, or even Phase 1.

\section{F. Comprehensive Product Safety}

Since product-safety engineering is integrated into the EDDTP, an entire safety system can be created to complement the designed-in safety characteristics of the product. These elements include owner's manuals, video content, warning labels, hangtags, point-of-sale materials, website content, and other materials as needed.

Each of these items must be consistent with the other items. If, for example, PPE in the form of a helmet must be worn whenever using the product, then all product materials-including advertising - must show helmets being used by product operators. Similarly, if there is a particular manner in which the product must be used, then no materials should ever show the product being used in another fashion. Although this point seems elementary, it is not uncommon to see inconsistent uses of a product between different company-produced materials. 
Although some warning labels are ridiculous, they can serve an important function when there is no other way to convey a hazard to a product user. Students are shown the correct way to construct warning labels based upon the ANSI method [26]. They are taught the differences between the signal words of DANGER, WARNING, CAUTION, and NOTICE as well as the correct use of the safety-alert symbol $\triangle$. Students are also shown differences between the ANSI warning label word-based approach and the ISO [27] warning-label pictogram approach.

\section{G. Product-Safety Methods \& Tools}

It is virtually impossible to design a product that is completely safe. Instead, an engineer must design a product with an acceptable level of safety. It is necessary to examine two aspects of safety in order to accomplish this. The first aspect of safety is how badly a person could be injured by a product; the second is how probable that product is to injure that person. Therefore, for each hazard, there is a Severity of injury as well as a Probability of injury. Those two aspects are frequently combined into a single function, Risk [28:7], as shown below.

$$
\text { Risk }=f(\text { Severity, Probability) }
$$

Students are shown the relationships between risk management, risk assessment, risk analysis, risk estimation, risk evaluation, risk reduction, and risk mitigation according to the international standard for machinery safety [29].

Elementary risk-analysis methods are demonstrated in the course and are the Preliminary Hazards List (PHL), Preliminary Hazards Analysis (PHA), and the Safety-Review Matrix (SRM). The first two methods are described in literature, e.g., [28]. The last method was developed by the first author during an EDDTP-type process. The SRM introduced is based on the PHA but has added elements of a comprehensive product-safety system. For each recognized hazard, the manner of addressing the risk is listed as well as where within the product-safety system that countermeasure is deployed. For example, if the product's operational environment is so hazardous that a helmet must always be worn, then the SRM might say that "Always wear a helmet when operating vehicle" will be clearly stated in the owner's manual, warning label, and elsewhere and that no non-helmeted operators will be shown in any product materials. The SRM may be updated for each safety review to document the progress of the design. The SRM taught has been aligned with Annex I of the European Machinery Directive [30:12-41]. Other directives, standards, agreements, and criteria may also be incorporated into these documents.

These documents should also be augmented to accommodate "at risk" users of the product. For example, if the product has hazards against which young or old consumers should be protected, a set of safety countermeasures may be designed to consider design features, educational materials, warning verbiage, warning location, and similar elements protective for such distinct populations of consumers. 
In addition to the methods mentioned above, students in the course are taught the fundamentals of Failure Modes and Effects Analysis (FMEA/FMECA) [31] and Fault-Tree Analysis (FTA) [32]. The coverage in this class is basic. Students with greater interest in these areas are encouraged to enroll in the System Safety course offered in the Department.

\section{H. Production \& Logistics}

Although Phase 4 of Figure 1 is usually beyond a discussion on engineering design, the Production \& Logistics stage is pertinent to both engineering and product safety. Problems affecting product safety can and do arise as products are manufactured and shipped. For this reason, Phase 4 is briefly covered in the course. Typical issues arising once final design is complete include mis-assembly, unspecified routings for cables and wires, and necessary reworking of product if some part missed its delivery time and production continued. Each of these means either additional design work or the potential for sub-standard product quality and safety.

\section{Post-Sale Remediation}

In recent years numerous product safety recalls have received much media attention. Frequently a company's image is tarnished by this adverse publicity. Financial penalties can also be significant. Industries affected by recalls include automotive, food, medical implants, and consumer products.

It is vital to remind students that a manufacturer's obligations to society do not end upon the sale and delivery of the product. Instead, companies have a duty to remedy or remove their unsafe products from the marketplace. In today's America, some entrepreneurs see the instant reward of a successful product without realizing the societal obligations attached to it. This part of engineering is rarely taught.

If a product has a safety defect, the manufacturer generally must remediate. Remediation can take the forms of buy-back, repair, and replacement. However, not all defects are safety defects. Some defects affect quality, performance, appearance, or another characteristic and pose no risk to consumer safety and health. However, those products with safety defects must be corrected. In some instances, the fault lies with a supplier or sub-supplier. Even though it may not be your company's fault, it becomes your company's problem.

A means of assessing potential product-safety problems must exist within a company. One such possible post-sale remediation model is discussed in the course. It includes four stages of remediation: Data Collection, Analysis, Decision, and Execution. The elements and mechanics of each stage of potential product-safety remediation are discussed along with possible interactions with consumers, regulators, suppliers, and employees. The model's flowchart contains a means for conducting a product-safety recall should one become necessary. 
To help assess the need for a product-safety recall, the European Commission's (EC) RapidAlert System (RAPEX) [33] and its criteria are covered since American regulators do not provide such specific guidance to companies. The EC provides a method for determining risk level based on severity and probability using tables to assess each aspect of risk.

\section{J. Guest Lecturers}

This product-safety and ethics course is supplemented by lectures from highly qualified experts in their respective fields. Lecturers have included consulting engineers, engineering professors, attorneys, and business consultants. While many guest lecturers reinforce subject matter already in the course, some lecturers - especially the attorneys - expand into areas not covered by the professor.

\section{K. Course Materials}

No suitable textbook has been found for the course. Instead, students are provided with internet links to publicly available materials. In addition to keeping cost down for students, many references are continually revised so that course material remains current. There are some materials for which agreements have been reached permitting distribution for educational-only use. Through this mix of course materials, the professor is also able to incorporate, as needed, current-event topics into the course lectures to demonstrate, or simply discuss, applicability to product-safety engineering.

\section{Discussion}

The student feedback from the product-safety course has been positive. Table 1 contains representative comments from the latest end-of-semester course evaluation (December 2017). Students said that the course content, including assignments and guest speakers, were good and brought with them real-world experiences. Students also appreciated that a new aspect of engineering was offered forcing one to "think critically and play the devils [sic] advocate on things." One student commented on "added insight" provided by the course as well as the ethical need to consider "societal implications." The comments also included student recommendations to their colleagues and multiple suggestions that this course be required of all undergraduate students.

These comments and personal interactions with students indicate success with both undergraduate and graduate students. One purpose of the course is to help students think critically about the decisions they will make ultimately affecting the public. It is hoped that students will exhibit critical thinking when examining choices to reach a rational conclusionrather than simply an opinion. 
Table 1. Sample Comments from Student Reviews of the Product-Safety Course.

\section{Question: Comments on course effectiveness}

The lectures and information shared were helpful in learning about product safety. The guest lecturers had fascinating industry insight that was extremely useful and beneficial.

The class presentations and the guest lecturers were excellent sources of information for this course.

made you think critically and play the devils advocate on things. product safety is a course that all should take $i$ think. not many students think of a lot of things that are covered in this class.

Great topics and necessary information for engineers

I appreciated the number of guest lectures that we were given, it gave us a chance to see face to face some industry professionals in their given fields. This gave us a chance to hear real world applications of what we were learning, this was very very helpful....

Excellent course content!

The homework and tests felt real, as in real world experience problems which is great.

The guest lecturers were great because they brought in real world experience and knowledge.

Guest lecturers were very interesting and I enjoyed the added insight they brought to the subject. The real-world application of this course is great. A course similar to this required for all undergraduate students would be great thing to drive home the importance of safety in design, and the societal implications of what we do as engineers.

Question: Instructor Comments

Guest lecturers were great. The homework assignments provided an opportunity to dive into product safety and different forms of safety evaluation methods that were very beneficial.

I tell everyone to take this class because it make you think about new aspects of engineering.

Helped the students to think about the situation and propose a solution without making students feel like there was only one right way

Real world life experiences shared with the class were very informative and helpful.

Although this course has been successful in many ways, there are challenges to offering such a course. Today's undergraduate-engineering curriculum is densely packed. There is little room for a dedicated product-safety engineering course as a requirement. Another complication is that specialized experience is desirable to teach such a course.

\section{Conclusions}

This paper outlines the curriculum of a product-safety engineering course with a focus on engineering ethics which has been taught to senior undergraduate students and graduate students at a major university for three years. The course starts with the NSPE Code of Ethics and its emphasis on always holding the safety, health, and welfare of the public as of paramount importance. Then discussed is that safety is a concept saddled with misconceptions and often confused with other concepts. The course continues with the dilemma faced by engineers who 
must be sure that the products they design and manufacture are safe for the public to use since what constitutes "safe" is never given to them. They themselves must ultimately decide the safety characteristics of their products. Therefore, an engineer's sense of ethics is vitally important in order to uphold NSPE obligations to the public.

This paper does not necessarily advocate engineering activism but, instead, points out to engineering students the responsibilities they have to themselves and to the public. Taking this course should result in students being more prepared to face the challenges of real-world engineering and to be in better control their own futures and protect the public when - not if ethical issues arise on the job.

The course trains engineering students to consider safety throughout the design process and offers engineering ethics as a vital aspect in an engineer's education because not all engineering problems are soluble with mathematics and physics. Students are taught to always act ethically and produce safe products. The public has long expected it, now demands it, but has always deserved it.

References

[1] Code of Ethics for Engineers, National Society of Professional Engineers, Alexandria, VA, Publication \#1102, July 2007, p. 1.

[2] Criteria for Accrediting Engineering Programs: Effective for Reviews During the 20182019 Accreditation Cycle, ABET, Baltimore, MD, USA, pp. 16, 42.

[3] A.J. McDonald and J.R. Hansen, Truth, Lies, and O-Rings: Inside the Space Shuttle Challenger Disaster. Gainesville, FL, USA: University Press of Florida, 2012.

[4] Reuters. "VW Engineer Sentenced to 40-Month Prison Term in Diesel Case." Internet: https://www.reuters.com/article/us-volkswagen-emissions-sentencing/vw-engineersentenced-to-40-month-prison-term-in-diesel-case-idUSKCN1B51YP, August 25, 2017 [January 17, 2018].

[5] New York Times. "Volkswagen Official Gets 7-Year Term in Diesel-Emissions Cheating." Internet: https://www.nytimes.com/2017/12/06/business/oliver-schmidt-volkswagen.html, December 6, 2018 [January 17, 2018].

[6] CNN. "The Costs of Volkswagen's Diesel Emissions Scandal Continue to Soar." Internet: http://money.cnn.com/2017/09/29/investing/volkswagen-diesel-cost-30-billion/index.html, September 29, 2017 [January 19, 2018].

[7] U. Sinclair, The Jungle. New York City, NY, USA: Doubleday Publishing, 1906. 
[8] U.S. CPSC, “CPSC Votes Lawn Dart Ban.” Internet: https://www.cpsc.gov/content/cpscvotes-lawn-dart-ban, May 25, 1988 [January 26, 2018]

[9] R. Nader, Unsafe at Any Speed: The Designed-In Dangers of the American Automobile. New York City, NY, USA: Grossman Publishers, 1965.

[10] U.S. FDA, "Rules and Rulemaking." Internet: https://www.fda.gov/RegulatoryInformation/RulesRegulations/, February 23, 2014 [January 25, 2018].

[11] European Commission. “CE Marking.” Internet: https://ec.europa.eu/growth/singlemarket/ce-marking_en, January 19, 2018 [January 19, 2018].

[12] R.L. Barnett and P. Barroso, Jr., "On Classification of Safeguard Devices (Part I).” Triodyne Safety Brief, vol. 1, no. 1, April 1981.

[13] R.L. Barnett and P. Barroso, Jr., "On Classification of Safeguard Devices (Part II)." Triodyne Safety Brief, vol. 1, no. 2, September 1981.

[14] R.L. Barnett and D.B. Brickman, "Safety Hierarchy.” Triodyne Safety Brief, vol. 3, no. 2, June 1985.

[15] R.L. Barnett, G.D. Litwin, and P. Barroso, Jr., "The Dependency Hypothesis (Part I)." Triodyne Safety Brief, vol. 2, no. 3, November 1983.

[16] R.L. Barnett, G.D. Litwin, and P. Barroso, Jr., "The Dependency Hypothesis (Part II) Expected Use.” Triodyne Safety Brief, vol. 3, no. 1, November 1983.

[17] R.L. Barnett and W.G. Switalski, "Principles of Human Safety." Triodyne Safety Brief, vol. 5, no. 1, February 1988.

[18] R.L. Barnett, "The Principle of Uniform Safety.” Triodyne Safety Brief, vol. 10, no. 1, August 1994.

[19] R.L. Barnett, “On Safety Codes and Standards.” Triodyne Safety Brief, vol. 2, no. 1, July 1983.

[20] R.L. Barnett and S.A. Glowiak, "Standards-Impact and Impotence." Triodyne Safety Brief, vol. 27, no. 2, November 2004.

[21] R.L. Barnett and S.R. Schmid, "Safeguard Evaluation Protocol—A Decision Tree for Standardizing, Optionalizing, Prohibiting, Ignoring, Enhancing, or Characterizing Safeguards.” Triodyne Safety Brief, vol. 11, no. 2, May 1995. 
[22] W. Haddon, Jr. (1968). "The Changing Approach to the Epidemiology, Prevention, and Amelioration of Trauma: The Transition of Approaches Etiologically Rather Than Descriptively Based," American Journal of Public Health. 58, pp. 1431-8.

[23] P.G. Dominick, J.T. Demel, W.M. Lawbaugh, R.J. Freuler, G.L. Kinzel, and E. Fromm, Tools and Tactics of Design. New York City, NY, USA: John Wiley \& Sons, Inc., 2001, p. 6.

[24] G. Pahl and W. Beitz, Engineering Design: A Systematic Approach. London, UK: Springer, 1996, p. 3.

[25] K.T. Ulrich and S.D. Eppinger, Product Design and Development (Second Edition). Boston, MA, USA: Irwin McGraw-Hill, 2000, p. 16.

[26] Product Safety Signs and Labels, ANSI Standard Z535.4-2011.

[27] Graphical Symbols—Safety Colours and Safety Signs-Part 2: Design Principles for Product Safety Labels, ISO 3862-2:2016.

[28] System Safety, U.S. Department of Defense Standard MIL-STD-882E, 2012.

[29] Safety of Machinery-General Principles for Design-Risk Assessment and Risk Reduction, ISO Standard 12100:2012.

[30] European Commission, "Directive 2006/42/EC of the European Parliament and of the Council of 17 May 2006 on Machinery, and amending Directive 95/16/EC (Recast)," Document EUR-Lex32006L0042. [Electronic]. Available: http://eur-lex.europa.eu/legalcontent/EN/TXT/?uri=CELEX:32006L0042.

[31] Procedures for Performing A Failure Mode, Effects and Criticality Analysis, Military Standard MIL-STD-1629A, 1980.

[32] Fault Tree Handbook with Aerospace Applications, Version 1.1, NASA Office of Safety and Mission Assurance, Washington, DC, 2002.

[33] Consumer Product Safety in Europe Corrective Action Guide: Guidelines for Businesses to Manage Product Recalls \& Other Corrective Measures, European Commission, Brussels, BE, 2011, p. 37. 